\title{
On the Farm
}

W

hen you sit down to the table to eat, you want to know that your food is safe.

Many consumers are looking to local farmers and farmers markets as a source for safe, nutritious, local foods.

Food safety begins on the farm. Produce must be planted, grown, harvested, stored and transported using a series of "best practices." These "best practices" help to prevent contamination of the product with harmful, disease-causing microorganisms (or pathogens, as they are called) and prevent growth of any harmful bacteria that may be present.

The goal of a food safety plan on your farm is to prevent produce from becoming contaminated and not to allow harmful bacteria to multiply to high enough numbers to cause illness. Older adults, young children and people with existing health problems are more susceptible to foodborne

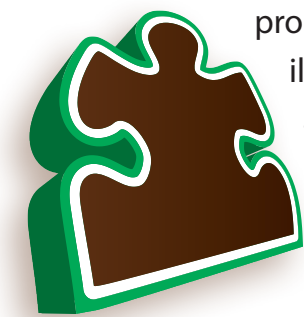
illness and severe complications than healthy adults. Food safety plans should strive to protect even these most vulnerable populations.

Think about a puzzle. When all of the pieces are put together, you can see a complete picture. If you just choose to use a few pieces, then you still will not have a complete picture. A food safety plan for keeping produce safe has many pieces (see Figure 1). If you just focus on one or two pieces, the product may still be unsafe. However, if you put all the pieces together, you have a plan for keeping your products safe.

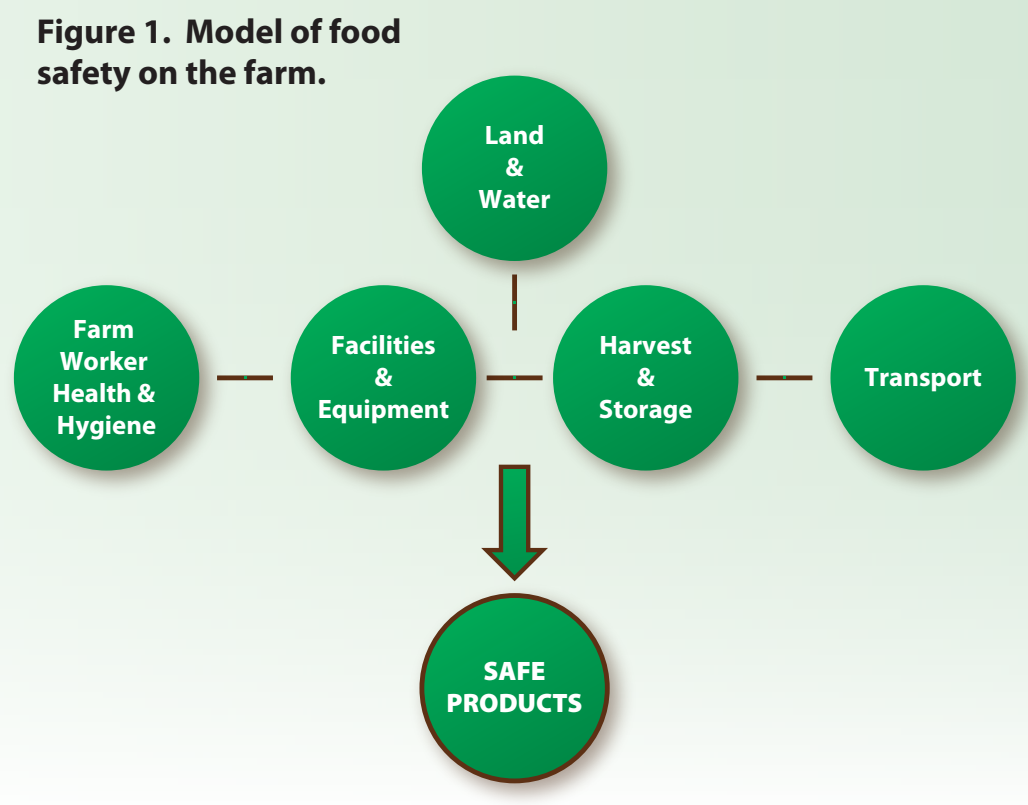

\section{Developing a food safety plan}

\section{1) Pay attention to particular areas on the farm where contamination might occur and affect the safety of the product.}

$\diamond$ Land use - Do you know how the land was used previously? Have you applied raw manure to the land and, if so, when? Are growing areas protected from run-off from nearby sources of contamination like animal holding areas, poultry houses, etc.? Do you try to keep animals, including pets, out of your growing areas?

$\diamond$ Water use - What water sources do you use for irrigation and crop sprays that will come in contact with the part of the crop that will be harvested? Have you had these sources tested to be sure bacterial counts will not affect the safety of your products?

$\diamond$ Worker health and hygiene - Do you train your workers on handwashing, good personal hygiene, what to do if they are sick or injured, etc.? 
$\diamond$ Facilities and equipment - Are appropriate and well-stocked toilet and handwashing facilities provided for workers; are facilities and equipment in good shape and cleaned and sanitized on a regular basis?

$\diamond$ Do you train your workers on how to monitor fields for signs of animal intrusion and not to harvest produce with visible signs of feces on it?

$\diamond$ Harvesting and storage - Is equipment clean and sanitized; are packing sheds clean and pest-free; are storage areas clean and temperature controlled; etc.?

$\diamond$ Transport - Are trucks or trailers cleaned and sanitized; are bins or boxes covered; is the temperature controlled to prevent the growth of harmful bacteria and to preserve quality?

\section{2) If someone cited your produce as a cause of illness, can you show that you took precautions to keep your products safe?}

$\diamond$ Training and certification - Do you have documentation that you have attended a food safety training; do you have records or evidence of training your workers? If your business grows, depending on the amount of produce and other foods you sell and who it is sold to, you or one person from your farm may need training that meets the requirements of the Food Safety Modernization Act's Produce Safety Rule.

$\diamond$ Documentation - Do you have good records of where you purchase seeds and supplies, lot numbers, dates when fertilizers or pesticides were applied, dates when produce is harvested after application, water test results, sanitation procedures, and storage temperatures? Having written records helps you show that you have procedures in place to keep your products safe.

$\diamond$ Could you trace each lot of product back to the particular plot where it was grown if there was a problem with your product?

\section{Why is it important to show you have made these efforts to keep products safe?}

Research by the Economic Research Service found that average costs of liability awards in court cases related to foodborne illness outbreaks in 1998 dollars were over $\$ 270,000$ when premature death occurred, over $\$ 140,000$ when hospitalization was necessary and over $\$ 110,000$ in other cases. Today, costs are in the millions of dollars and may even include sentencing in a court of law.

Making someone ill or causing a death due to foodborne illness can be devastating not just for you and your farm, but also for the entire "locally grown" agriculture market. Having a written food safety plan is a way to protect yourself and others. For more information, see additional Enhancing the Safety of Locally Grown Produce factsheets on specific components of the food safety model. 